\title{
Program Pemberdayaan Masyarakat non Produktif tentang pentingnya Manfaat mengenal dan menjadi Donor Darah di Unit Tranfusi Darah PMI Kota Surabaya
}

\author{
Hasdianah H. Rohan ${ }^{1 *}$, Sasi Widuri' ${ }^{2}$, Yustisia Amalia ${ }^{3}$ \\ ${ }^{1,2,3}$ Fakultas Ilmu Kesehatan, Universitas Dr. Soetomo Surabaya, Indonesia \\ *dzaskiyah111111@gmail.com
}

Received 21 August 2019; Accepted 28 August 2019; Published 5 September 2019

\begin{abstract}
Blood transfusion service is a health care effort that utilizes human blood as a basic ingredient with humanitarian purposes and not for commercial purposes. Blood transfusion services as one of the health efforts in order to cure disease and health recovery desperately require the availability of blood or adequate blood components, safe, accessible and affordable by the community. Each blood transfusion unit has a responsibility to meet the availability of blood in its working area. Blood availability is highly dependent on the willingness and awareness of people to donate their blood voluntarily and regularly. To achieve this, blood transfusion units need to conduct donor recruitment activities which include socialization efforts and campaign of voluntary blood donor, donor deployment and donor preservation. The need for blood is increasing in this world where 1 patient from 7 patients who are hospitalized requires a blood transfusion. Imbalance between blood supply and blood needs is increasing in the world. Currently only in 62 countries, blood supplies of $100 \%$ are derived from voluntary blood donors and 40 other countries still depend on family darai donors and paid blood donors. From the results of location analysis and info from blood transfusion Unit RS, Dr. Setomo, Surabaya PMI about the problems of lack of blood stocks at a certain moment, then make us perform a lack of public awareness about the blood Donor This, thereby giving our infiration to give intervention, counseling, convey that being a blood Donor can increase the stamina and occurrence of new erythrocytes, which can facilitate blood circulation and make the body healthier. Plan, create a community Web Site that is interested in becoming a voluntary blood Donor, so that the community is moved to become a voluntary blood Donor, of course not be separated must fulfill the requirements that the blood donation is worthy as Blood and healthy Donor, appropriate Perturan. Install Bener on a specific place, make a bag, T-shirt, key toy, a zipper box, and other knacks that can be used as the community Logo voluntary blood donor, in hopes of increasing the necessary blood stocks society. From the new results we perform to attract voluntary blood donors. Through the appeal to come to the counseling and to share Leaflet only at this early stage, there have been obtained result of increased blood stock from the results of voluntary blood donation after Community service. Obtained significant results, where there is an increase in the amount of blood in PMI, after the implementation of blood donation. There is an increase in blood stocks at that time as much as $40-50 \%$, from the results of community devotion.
\end{abstract}

Kata kunci: Blood stocks, PMI, blood donor recruitment, blood donor community

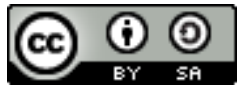

This is an open-acces article distributed under the terms of the Creative Commons Attribution-ShareAlike 4.0 International License. 


\section{PENDAHULUAN}

Kebutuhan darah setiap hari di negara seperti United States, adalah sekitar 36.000 unit sel darah merah tetapi hanya 13,6 juta unit sel darah merah yang dapat dikumpulkan dalam satu tahun. Hanya $10 \%$ dari populasi yang memenuhi syarat benar-benar mendonorkan darahnya setiap tahun, meskipun diperkirakan 38\% dari populasi United States memenuhi syarat untuk mendonorkna darahnya (The American National Red Cross, 2016).Jumlah kebutuhan minimal unit darah di Indonesia telah mencapai sekitar 5,1 juta unit kantong per tahun atau $2 \%$ jumlah penduduk, sedangkan penyedia darah dan komponennya saat ini hanya sebanyak 4,6 juta kantong dari 3,05 juta donasi. Sebanyak $86,20 \%$ dari 3,05 juta donasi itu berasal dari donor darah sukarela. Indonesia masih kekurangan jumlah penyediaan darah secara nasional sekitar 500 ribu kantong (Kementerian Kesehatan Republik Indonesia, 2016).

Palang Merah Indonesia menargetkan hingga 4,5 juta kantong darah sesuai dengan kebutuhan darah nasional disesuaikan dengan Standar Lembaga Kesehatan Internasional (WHO) yaitu 2\% dari jumlah penduduk untuk setiap harinya. Jumlah donor darah di Indonesia relatif rendah, dimana terdapat 250 ribu pendonor tetap dengan perbandingan populasi di Indonesia sekitar 230-240 juta jiwa. Hal ni menunjukkan rendahnya tingkat kesadaran di alangan masyaraat untuk menjadi pendonor darah sukarela (Palang Merah Indonesia, 2009).Pentingnya ketersediaan darah di bank darah rumah sakit untuk memenuhi kebutuhan akan trnasfusi darah yang dapat terjadi kapan saja seperti untuk korban kecelakaan yang dalam kondidi gawat darurat yang membutuhkan transfusi darah, pasien operasi mayor seperti operasi jantung, bedah abdomen, ibu melahirkan, penderita penyakit darah seperti Thalasemia, namun ketersediaan unit darah sering kali tidak mencukupi kebutuhan masyarakat. Kurangnya pengetahuan masyarakat tentang manfaat donor darah bagi kesehatan si donor dan banyaknya mitosmitos yang berkembang di Indonesia tentang dampak negatif dari donor darah sering menyebabkan hal ini berlaku. Beberapa mitos negatif yang berkembang di masyarakat seputar donor darah antara lain, yaitu donor darah membuat kita gemuk, membuat badan lemas, wanita tidak boleh mendonorkan darah, menimbulkan kecanduan. (Palang Merah Indonesia, 2009).

Kebutuhan darah ini merupakan hal yang urgen, Darah nerupakan materi biologis yang hidup yang belum dapat diproduksi di luar tubuh manusia. Artinya ketersediaan darah di sarana kesehatan sangat ditentukan oleh partisipasi masyarakat dalam mendonorkan darahnya.Selain itu ketersediaan darah juga ditentukan oleh ketersediaan fasilitas, sarana dan prasarana yang dapat menjamin ketersediaan darah dalam jumlah yang cukup, aman dan berkualitas. Pelayanan darah merupakan tanggungjawab pemerintah pusat dan pemerintah daerah yang pelaksanaannya dilakukan melalui Unit Transfusi Darah (UTD) dan Bank Darah Rumah Sakit (BDRS).Darah yang aman merupakan darah yang berasal dari donor resiko rendah, yang salah satunya bisa didapat dari donor darah sukarela. Hal ini penting untuk diperhatikan mengingat darah juga dapat menjadi media penularan penyakit seperti HIV, Hepatitis B, Hepatitis C dan Sifilis.Hal ini sesuai dengan amanat UU kesehatan no 36 tahun 2009 dan PP no 7 tahun 2011 tentang Pelayanan Darah serta rekomendasi WHO bahwa darah transfusi yang aman dan berkualitas berasal dari donor sukarela. Informasi dan edukasi merupakan strategi penting dalam rekrutmen donor. Strategi yang tepat merupakan kunci keberhasilan rekrutmen donor. Tujuan edukasi adalah untuk merubah pemahaman dan perilaku masyarakat dalam hal :Manfaat darah pentingnya mendonasikan darah secara sukarela dan teratur. Perilaku berisiko yang dapat mempengaruhi keamanan dan mutu darah.

\section{BAHAN DAN METODE}

Pendonor Sukarela diberi Intervensi dan Penyuluhan tentang Manfaat sebagai Donor Darah.,karena Masyakat masih ada yang belum mengerti dan memahami pentingnya melakukan donor darah mengingat darah dan komponen darah sangat dibutuhkan untuk keperluan transfuse darah. Transfusi darah sebagai salah satu upaya pemulihan kesehatan sangat membutuhkan ketersediaan darah darah yang cukup, aman mudah diakses dan terjangkau oleh masyarakat.Pembagian Leaflet, pemasangan Bener.

Pengarahan tentang kesehatan dalam intervensi ,menyadarkan Masyarakat ternyata donor darah tersebut memang baik untuk kesehatan ,membuat stamina terjaga,peredaran darah lancer,dan mencegah timbulnya penyakit di dalam tubuh.Dengan adanya donor darah Sukarela ini menghasilkan pemasukan

\section{Journal of Community Engagement in Health


darah ke PMI meningkat,dibandingkan sebelum adanya donor darah,ditambah lagi adanya Komunitas donor darah, yang dapat bersinergis dalam Upaya meningkatkan Persediaan darah di PMI.

\section{HASIL}

Penyuluhan kepada masyarakat mengenai manfaat dan pentingnya melakukan donor darah Donor darah yang dilakukan di Universitas dr Soetomo. Telah dilakukan kegiatan penyuluhan tentang manfaat melakukan donor darah, sehingga masyarakat mengerti dan memahami manfaat donor darah serta pentingnya melakukan donor darah. Kegiatan donor darah di Fakultas Ilmu Kesehatan Universitas dr Soetomo tanggal 28 Juni 2019 dengan jumlah pendonor mencapai 33 orang yang terdiri dari pendonor yang sudah pernah donor sebanyak 10 orang dan donor baru 23 orang.

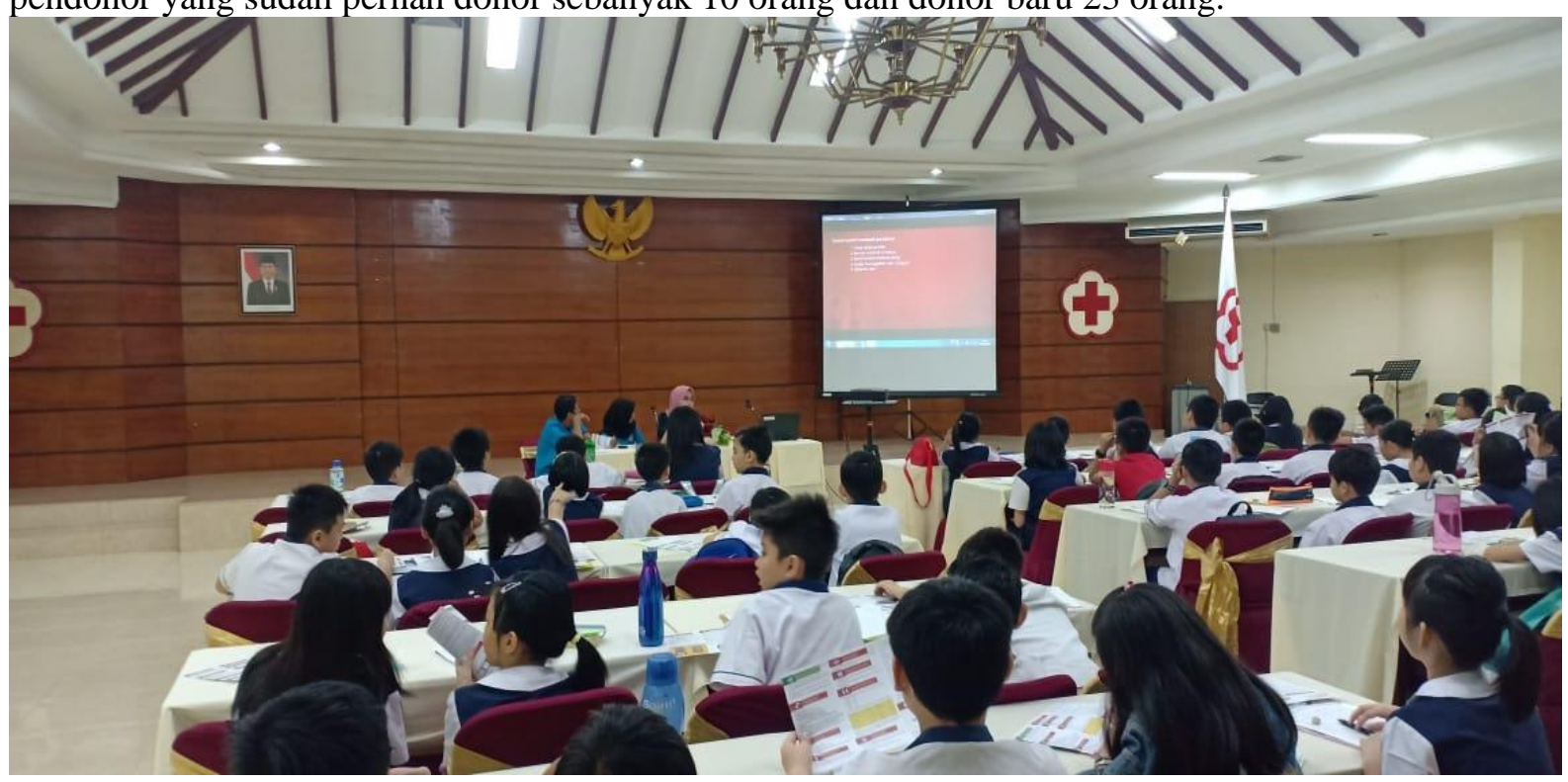

Gambar1 : kegiatan penyuluhan
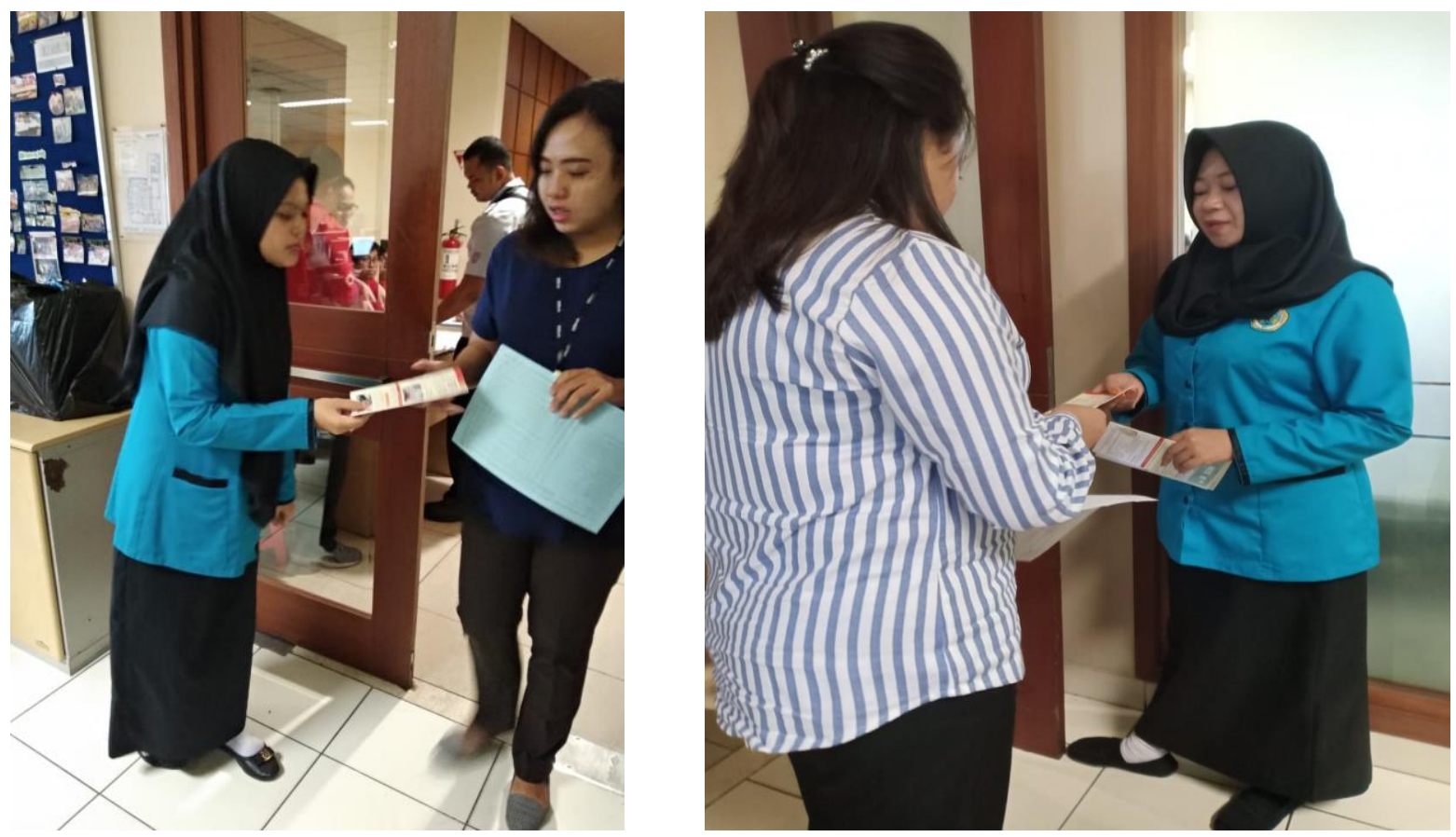

\section{Journal of Community Engagement in}


Gambar 2 : Memberikan leaflet kepada masyarakat sebagai salah satu kegiatan sosialisasi kepada masyarakat
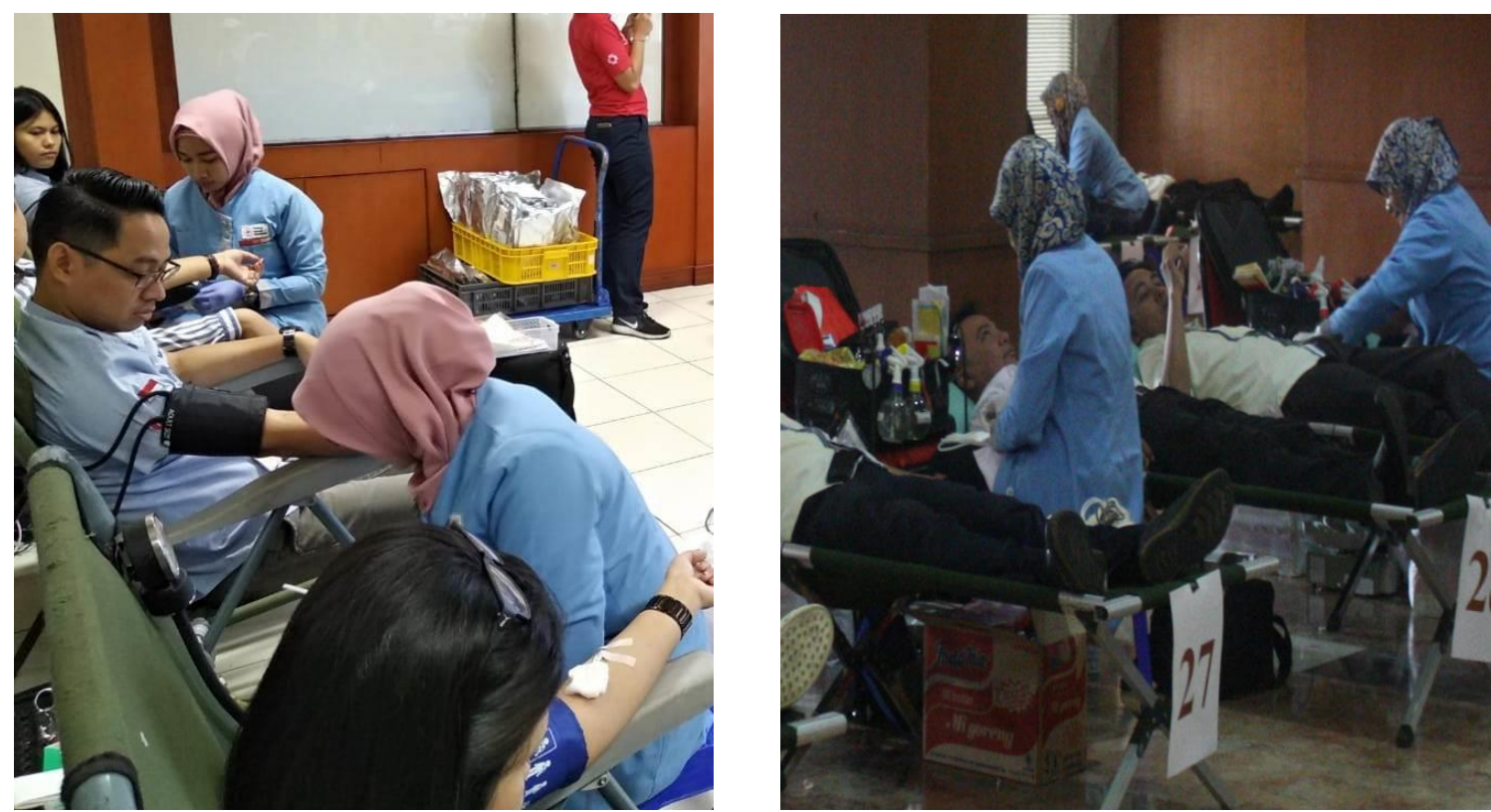

(A) (B)

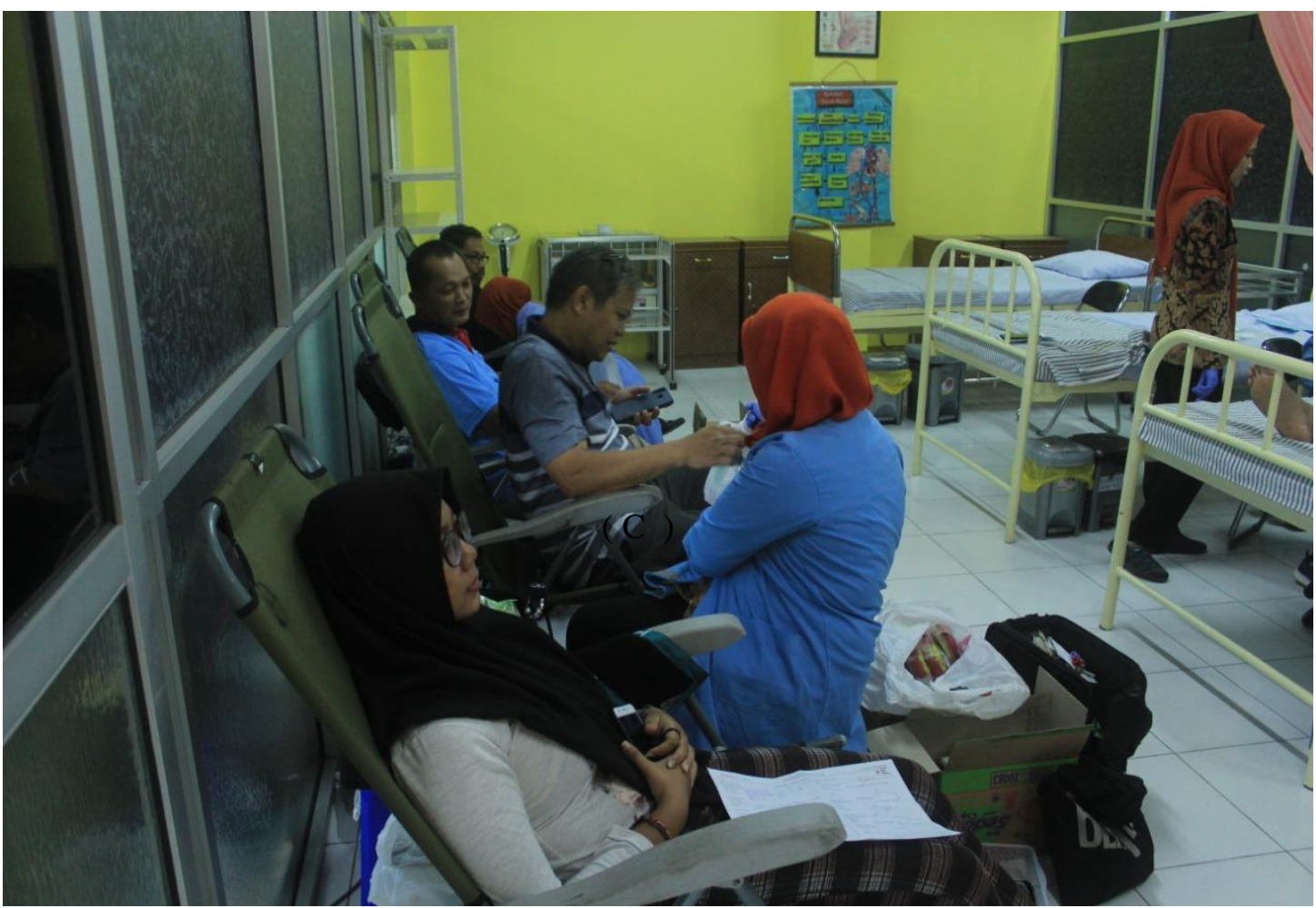

Journal of Community Engagement in 

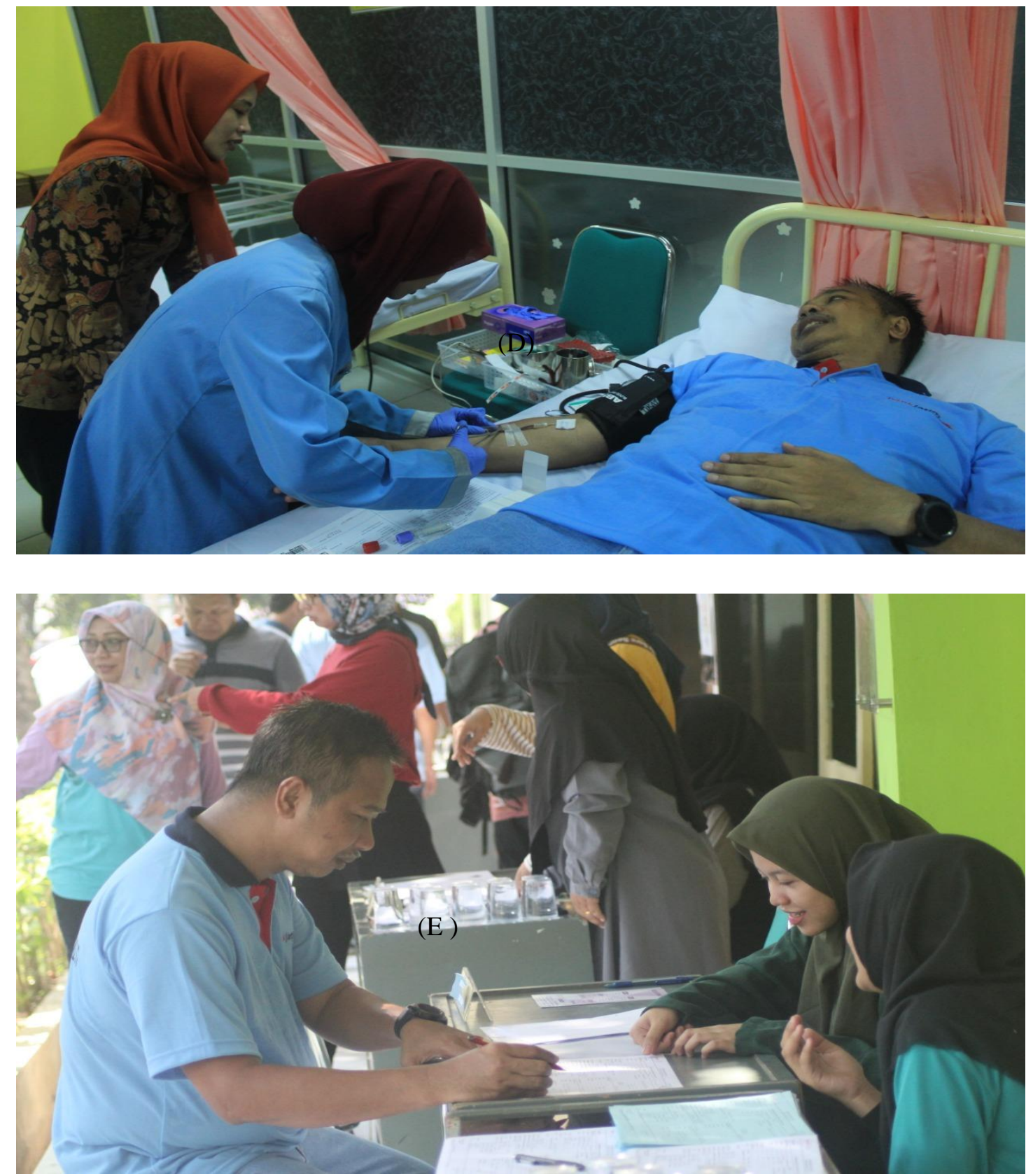

Gambar 3 A,B,C,D,E, : Kegiatan donor darah

\section{PEMBAHASAN}

Kegiatan berjalan dengan sangat baik. Seluruh peserta antusias dan Pro aktif terhadap kegiatan yang berlangsung. Masyarakat sekitar Kamus Unitomo ,Dosen,dan Mahsiswa bergabung mendengarkan Penyuluhan dan memperhatikan dengan seksama,dan membuat mereka mulai mengerti apa artinya Donor Darah,dan Manfaat Donor Darah.

Selama ini masih ada Pemikiran bahwa menjadi Donor darah nanti bisa gemuk dan lain sebagainya, pemikiran demikian mulai hilang, dan ditambah dengan adanya penyuluhan ini, juga pembagian leaflet, dapat membuat masyarakat mengerti bahwa Donor darah itu sebenarnya membuat Tubuh menjadi lebih Sehat. Peserta sangat antusias terhadap materi penyuluhan tentang Pentingnya menjadi Donor Darah Sukarela yang diberikan oleh TIM Pengabdian Masyarakat FIKES UNITOMO. Pihak Masyarakat berharap akan adanya Penyuluhan yang sama diwaktu berikutnya.

\section{Journal of Community Engagement in}

\section{Health}




\section{KESIMPULAN}

Dengan adanya Pengabdian Masyarakat akan bermanfaat bagi Masyarakat yang sebelumnya belum tahu tentang Donor darah dan Manfaatnya,,sekarang dengan adanya Penyuluhan dan ,Pembagian Leaflet menambah Pengetahuan Masyarakat mereka jadi Tahu,dan antusias untuk menjadi Donor Darah.Dengan meningkatnya minat Masyarakat untuk menjadi Donor darah, diharapkan kebutuhan akan darah di PMI dan kebutuhan Masyarakat akan terpenuhi.

\section{UCAPAN TERIMA KASIH}

Ucapan terimakasih TIM Pengabdian Masyarakat disampaikan untuk pihak-pihak yang telah membantu dalam mensukseskan kegiatan, khususnya untuk Universitas Dr. Soetomo Surabaya yang telah mendanai kegiatan Pengabdian Masyarakat ini.

\section{REFERENSI}

Peraturan Menteri Kesehatah Republik Indonesia nomor 91 tahun 2015 tentang Standar Pelayanan Transfusi Darah.

Pedoman Cara Pembuatan Obat yang baik di Unit Transfusi Darah (UTD) dan Plasmaferesis, BPOM, 2017. 